Article

\title{
Investigation of the Biological Applications of Biosynthesized Nickel Oxide Nanoparticles Mediated by Buxus wallichiana Extract
}

\author{
Salah Ud Din ${ }^{1}$, Hina Iqbal ${ }^{1}$, Sirajul Haq ${ }^{1, *} \mathbb{C}$, Pervaiz Ahmad ${ }^{2}$, , Mayeen Uddin Khandaker ${ }^{3}$ (D), \\ Hosam O. Elansary ${ }^{4}{ }^{\circ}$, Fatemah F. Al-Harbi ${ }^{5}$, Shaimaa A. M. Abdelmohsen ${ }^{5}$ and Tarek K. Zin El-Abedin ${ }^{6}$
}

Citation: Din, S.U.; Iqbal, H.; Haq, S.; Ahmad, P.; Khandaker, M.U.;

Elansary, H.O.; Al-Harbi, F.F.; Abdelmohsen, S.A.M.; El-Abedin, T.K.Z. Investigation of the Biological Applications of Biosynthesized Nickel Oxide Nanoparticles Mediated by Buxus wallichiana Extract. Crystals 2022, 12, 146. https://doi.org/10.3390/ cryst12020146

Academic Editor: Philip Lightfoot

Received: 15 December 2021

Accepted: 15 January 2022

Published: 20 January 2022

Publisher's Note: MDPI stays neutral with regard to jurisdictional claims in published maps and institutional affiliations.

Copyright: (c) 2022 by the authors. Licensee MDPI, Basel, Switzerland. This article is an open access article distributed under the terms and conditions of the Creative Commons Attribution (CC BY) license (https:/ / creativecommons.org/licenses/by/ $4.0 /)$.
1 Department of Chemistry, University of Azad Jammu and Kashmir, Muzaffarabad 13100, Pakistan; salah.mahsud@ajku.edu.pk (S.U.D.); hinaiqbal787@gmail.com (H.I.)

2 Department of Physics, University of Azad Jammu and Kashmir, Muzaffarabad 13100, Pakistan; pervaiz_pas@yahoo.com

3 Center for Applied Physics and Radiation Technologies, School of Engineering and Technology, Sunway University, Bandar Sunway 47500, Selangor, Malaysia; mayeenk@sunway.edu.my

4 Plant Production Department, College of Food and Agriculture Sciences, King Saud University, Riyadh 11451, Saudi Arabia; helansary@ksu.edu.sa

5 Department of Physics, College Science, Princess Nourah Bint Abdulrahman University, P.O. Box 84428, Riyadh 11671, Saudi Arabia; ffalharbi@pnu.edu.sa (F.F.A.-H.); shamohamed@pnu.edu.sa (S.A.M.A.)

6 Department of Agriculture \& Biosystems Engineering, Faculty of Agriculture (El-Shat By), Alexandria University, Alexandria 21545, Egypt; drtkz60@gmail.com

* Correspondence: cii_raj@yahoo.com or siraj.ulhaq@ajku.edu.pk

\begin{abstract}
The preparation of nickel oxide nanoparticles (NiO NPs) was carried out using an environmentally friendly and novel green synthetic strategy that included the use of Buxus wallichiana leaf extract as a reducing agent. Energy-dispersive X-ray (EDX), Fourier-transform infrared spectroscopy (FTIR), diffuse reflectance spectroscopy (DRS), X-ray diffraction (XRD), scanning electron microscope (SEM), and thermogravimetric analysis (TGA) techniques were used to characterize the resulting $\mathrm{NiO}$ NPs. At various concentrations, NiO NPs were tested for their percentage scavenging activity against the ABTS (2,2'-azinobis-(3-ethylbenzothiazoline-6-sulphonic acid) free radical, with an IC50 value of $234.84 \mathrm{~g} / \mathrm{L}$. Furthermore, the bactericidal activity of NiO NPs was studied by the agar well diffusion method against two Gram-positive bacterial strains (B. licheniformis and B. subtilis) and two Gram-negative bacterial strains (E. coli and K. pneumoniae).
\end{abstract}

Keywords: Buxus wallichiana; nickel oxide; microscopy; antioxidant; antibacterial

\section{Introduction}

The world's human population has been facing many serious health challenges since ancient times. Microorganisms such as viruses, bacteria, fungi, and pathogens have created a pandemic environment by causing many infectious disorders. Usually, Gram-positive and Gram-negative bacterial strains are among major public health threats. These are responsible for rapidly spreading infectious diseases [1,2]. Serious research is required to develop proficient antibacterial agents in this rapidly emerging technological era. Pharmacological and medical industries have prepared various types of antibiotics to control these diseases; however, these antibiotics sometimes lead to antagonistic/allergic side effects and infections $[3,4]$. Therefore, there is a need for a new emerging nanotechnology which can fight against pathogenic disorders [5].

In this regard, nano materials play effective roles as nontargeted disinfectants (for pathogens, microorganisms, and contaminants), as good antioxidant/antibacterial agents and photo catalysts, as removing agents for pollutant dyes, and as sensors of heavy metal ions [6]. Nanoscale materials such as $\mathrm{Ag}_{2} \mathrm{O}, \mathrm{CuO}, \mathrm{CoO}, \mathrm{SnO}_{2}, \mathrm{ZnO}, \mathrm{PtO}_{2}$, and, more 
importantly, $\mathrm{NiO}$, have gained significant attention due to their significant activity against bacteria $[7,8]$. NiO NPs have the ability to counter the generated free radicals and inhibit the oxidation/reduction potential of various species. Due to its outstanding electrical, optical, magnetic, catalytic, chemical, thermal, and mechanical properties, it has received considerable attention during the past decades [9]. Usually, the antibacterial phenomenon depends on nano size of particle, large surface area, reactive radicals $\left(\mathrm{Ni}^{2+}\right)$, and reactive species of oxygen (ROS). The nanoparticles of $\mathrm{Ni}$ are well-known antibiotics having the ability to produce reactive oxygen species (ROS) such as peroxide, superoxide, hydroxyl radicals, and singlet/alpha oxygen following the Fenton reaction. All these reactive species penetrate into bacterial cells and disturb the cytoplasm, which ultimately leads to bacterial death $[10,11]$.

Nickel oxide nanoparticles have been synthesized via green synthesis by different researchers around the world using different plant extracts and characterized for unique physiochemical properties as well as biological applications [12]. Green synthesis avoids the synthesis of annoying waste products and harmful materials through the production of suitable, easier, simple, and ecofriendly synthesis procedures. The present study, therefore, emphasizes the antioxidant and antibacterial effect of biogenic nano-sized nickel oxide via Buxus wallichiana plant. This plant belongs to the family Buxaceae, called Himalayan tree, and is found in Asia, especially in Pakistan [13]. This plant is a big source of antioxidants containing terpenoid, polar flavonoid, nonpolar flavonoid, tannin, saponin, phenol, and ascorbic acid with distinct ability to scavenge the function of free radicals. Biogenic $\mathrm{NiO}$ NPs were tested in the present investigation for their antioxidant properties as well as their antibacterial potential against the two Gram-positive and two Gram-negative bacterial strains. Bacillus species causes headache, vomiting, and diarrhea in human beings. Escherichia coli induce milk spoilage and is also present in contaminated foods. Thus, $\mathrm{NiO}$ NPs are biogenically prepared to overcome, prevent, and control these issues [14].

\section{Materials and Methods}

\subsection{Synthesis of $\mathrm{NiO} N \mathrm{NS}$}

To prepare the extract, $1000 \mathrm{~mL}$ deionized water was added to leaves of $B$. wallichiana, which were then boiled for three hours. Filtered through filter paper, the resulting extract was stored for later use. In the titration flask, $2.24 \mathrm{~g}$ of nickel nitrate hexahydrate (SigmaAldrich, St. Louis, MO, USA) was dissolved in $50 \mathrm{~mL}$ distilled water to create the precursor salt solution. The prepared plant extract was then added in $20 \mathrm{~mL}$ increments. The reaction mixture was stirred and heated for $30 \mathrm{~min}$ at $60^{\circ} \mathrm{C}$. The $\mathrm{pH}$ was adjusted to 10 with a solution of sodium hydroxide (Sigma-Aldrich), and the NiO gel was aged for $6 \mathrm{~h}$ and was eroded with deionized water and parched at $100{ }^{\circ} \mathrm{C}$ and stored.

\subsection{Characterization}

The XRD was performed at 2-theta ranges of $20^{\circ}$ to $80^{\circ}$ using a Panalytical X'pert pro (PW 3040/60) diffractometer. A Carl Zeiss Supra 40 FESEM model JEOL 5910 (Japan) was run to examine the surface morphology. X-ray dispersive spectroscopy was operated to examine the elemental ratio and pureness of the NiO NPs. During DRS analysis, the UV-visible absorption was observed, and the band energy was calculated via Tauc's plot. A Shimadzu FTIR spectrophotometer model $8400 \mathrm{~S}$ was used to perform the Fourier-transform infrared (FTIR) measurement.

\subsection{Antioxidant Assay}

The antioxidant potential of the NiO NPs was investigated using $\mathrm{ABTS}^{+} \bullet$ stabilizing assay, where the $\mathrm{ABTS}^{+} \bullet$ were generated in the dark by mixing $7 \mathrm{mM}$ ABTS solution and $2.5 \mathrm{mM} \mathrm{K} \mathrm{S}_{2} \mathrm{O}_{8}$ for $16 \mathrm{~h}$. Afterward, the absorbance was checked at $734 \mathrm{~nm}$ and $\mathrm{NiO}$ solution was simultaneously prepared by dissolving suitable amount ( 50 to $300 \mathrm{~g} / \mathrm{mL}$ ) in DMSO and was mixed with $1 \mathrm{~mL} \mathrm{ABTS}{ }^{+}$solution. The absorbance was checked at 734 
$\mathrm{nm}$ and the percentage activity was calculated via Equation (1), where $A_{i}$ and $A_{o}$ are the absorbance of test and control sample, respectively.

$$
\% \operatorname{RSA}=\left[\left(\mathrm{A}_{\mathrm{O}}+\mathrm{A}_{\mathrm{i}} / \mathrm{A}_{\mathrm{o}}\right)\right] \times 100
$$

\subsection{Antibacterial Assay}

Bactericidal effect of NiO NPs was checked against the nominated bacteria via agar well diffusion method, where the $24 \mathrm{~h}$ old culture was spread over the freshly prepared agar media, transferred into a Petri dish, and solidified at room temperature; the wells of $5 \mathrm{~mm}$ were bored with a sterile needle. The $\mathrm{NiO}$ dispersion in DMSO was dropped in the well and incubated at $37^{\circ} \mathrm{C}$, and the zones around wells were determined in mm after $24 \mathrm{~h}$.

\section{Results}

The NiO NPs were made using B. wallichiana leaves extract and a green method. The method was found to be safe and simple to use, though the exact mechanism for the plantaided synthesis of NPs is not reported yet. However, it is understood that the hydroxyl group containing phytochemicals plays an essential role in the synthesis [15]. The proposed mechanism is shown in Figure 1. The physicochemical, bactericidal, and antioxidant properties of the substance were investigated, and the results are presented below.

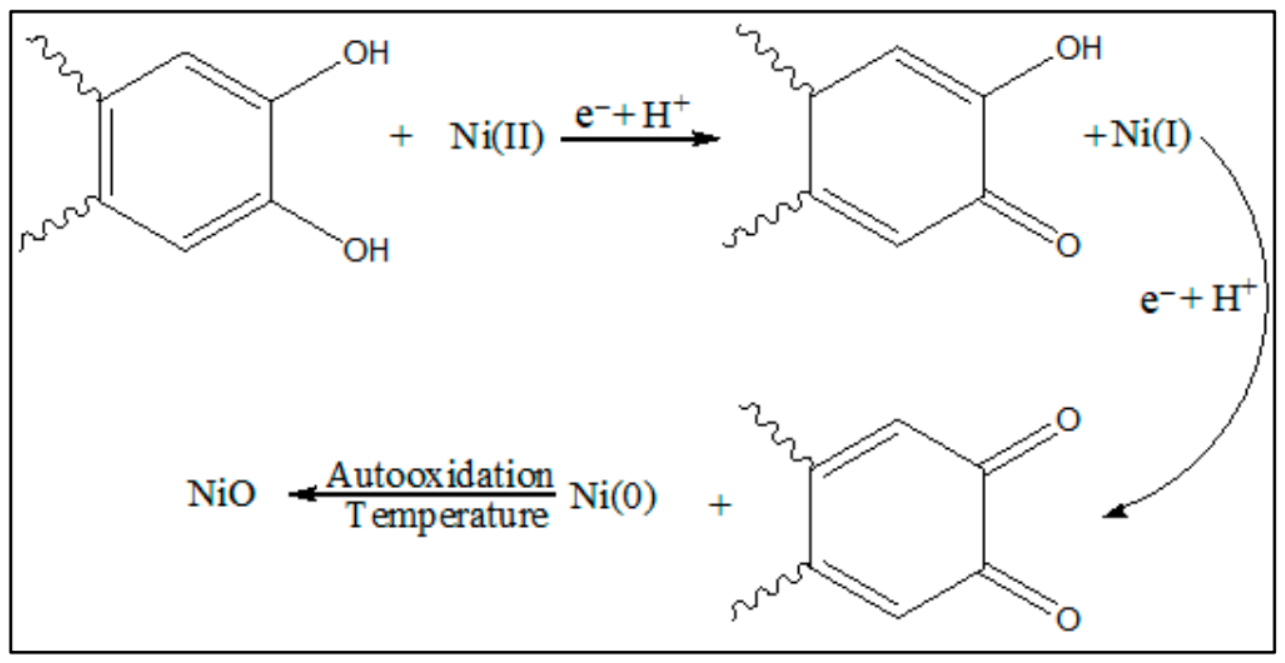

Figure 1. Suggested mechanism for the synthesis of $\mathrm{NiO}$ by green method.

\subsection{Characterization of $\mathrm{NiO} N \mathrm{NS}$}

\subsubsection{XRD Analysis}

Structural parameters such as geometry, lattice strain, and crystallite size of biogenic nanoparticles of $\mathrm{NiO}$ were explained through $\mathrm{X}$-ray diffraction analysis. XRD pattern of prepared sample of biogenic NiO NPs is shown in the X-ray diffractogram and represented in Figure 2. The broadness in different diffraction peaks of XRD indicates that particles are crystalline, narrow, and smaller in size in the nanometers range. XRD peaks confirmed the pure nature of biogenically synthesized NiO NPs due to the absence of other contaminant peaks in the XRD spectrum. The X-ray diffraction pattern shows three prominent peaks at $2 \theta=37.31,43.43$, and 63.01 with corresponding miller indices $=111,200$, and 220. This peak indexing matched with JCPDS card No. 01-073-151, confirming the face-centered-cubic (FCC) crystalline structure of $\mathrm{NiO}$ nanoparticles. Moreover, the crystalline size " $\mathrm{D}$ " and lattice constant " $a$ " were calculated by the given equations.

$$
\begin{gathered}
D=k \lambda / \beta \cos \theta_{B} \\
a=d_{h k l}\left(h^{2}+k^{2}+l^{2}\right)^{1 / 2}
\end{gathered}
$$




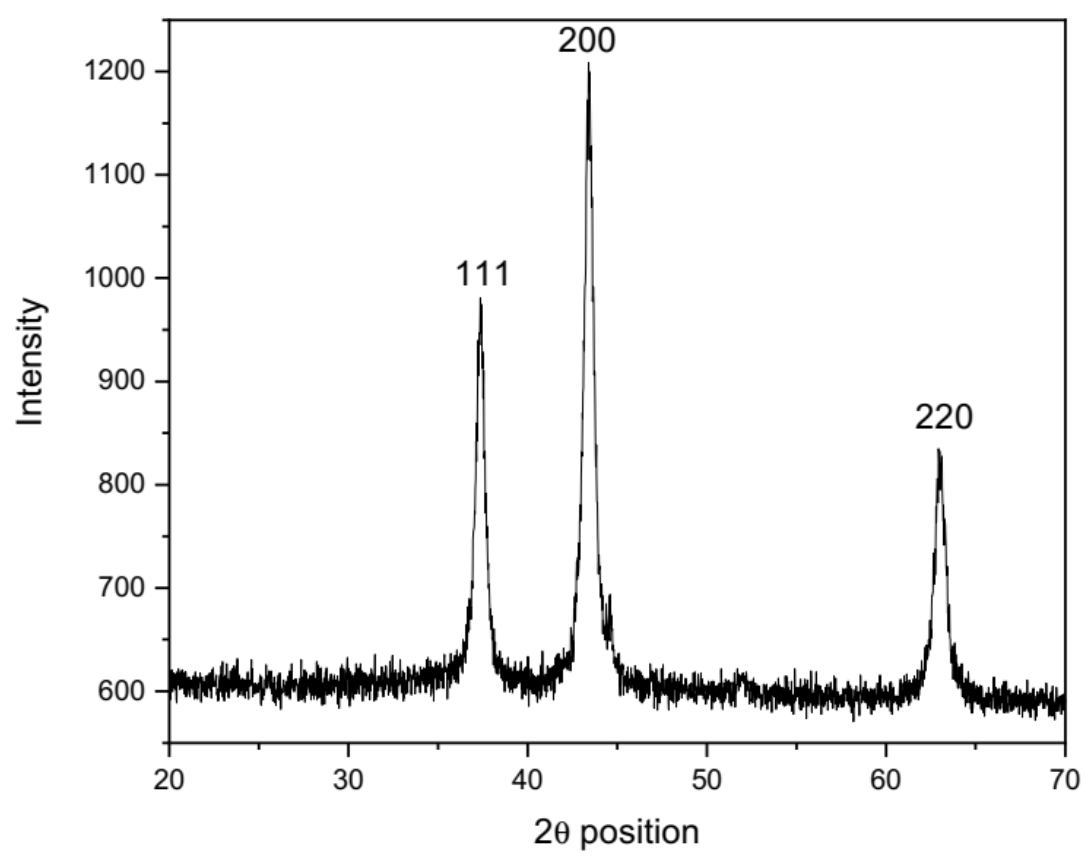

Figure 2. XRD pattern of biogenically synthesized NiO NPs.

Equation (2) is the well-known Debye-Scherrer equation which estimates the average crystallite size of NiO NPs. Here, $\mathrm{k}$ is an empirical constant that depends upon crystallite shape having value 0.89 or $0.9, \lambda$ is the wavelength of the $X$-ray $(0.15406 \mathrm{~nm} / 1.54 \AA), \beta$ is FWHM (full width at half maximum) or integral breath, and $\theta_{B}$ is Bragg angle. Equation (3) is used to calculate lattice constant "a" (Table 1), where d is interplanar spacing of crystalline sample and hkl are miller indices. The average crystalline size of biogenic $\mathrm{NiO}$ NPs estimated by Debye-Scherrer equation is $24.2 \mathrm{~nm}$ having $0.387 \%$ lattice strain which also matches well with the literature [16]. Thus, XRD confirms the highly crystalline nano size of the $\mathrm{NiO}$ under study.

Table 1. Calculated interplanar spaces (d) and lattice constant (a).

\begin{tabular}{|c|c|c|c|}
\hline $\begin{array}{l}\text { Miller Indices } \\
\text { (hkl) }\end{array}$ & $\begin{array}{l}\text { Peak Position Theta } \\
\text { Value in Degrees }\end{array}$ & $\begin{array}{c}\text { Interplanar Space (d) } \\
2 \mathrm{~d} \sin \theta=\lambda\end{array}$ & $\begin{array}{c}\text { Lattice Constant } \\
a=\operatorname{dhkl}\left(h^{2}+k^{2}+l^{2}\right)^{1 / 2}\end{array}$ \\
\hline 111 & 37.31 & 0.24 & 0.41 \\
\hline 200 & 43.43 & 0.22 & 0.44 \\
\hline 220 & 63.01 & 0.29 & 0.81 \\
\hline
\end{tabular}

\subsubsection{FTIR Analysis}

The identification of the functional groups in the band range of $400-4000 \mathrm{~cm}^{-1}$ by $\mathrm{KBr}$ disc pallet method was performed by FTIR characterization. The FTIR spectrum is shown in Figure 3, where the peak at $3708.61 \mathrm{~cm}^{-1}$ corresponds to the nonbonding water molecule. The broad peaks centered at $3449 \mathrm{~cm}^{-1}$ are due to broadening vibration of water $\mathrm{O}-\mathrm{H}$ bands that indicate the presence of hydroxyl group in carboxylic and phenolic acids [17]. Another peak at $1655.81 \mathrm{~cm}^{-1}$ refers to the water bending vibrations modes. The weak band observed at $1383.31 \mathrm{~cm}^{-1}$ indicates the deformation vibration of $\mathrm{NO}_{3}{ }^{-}$which is caused by the stretching of symmetric nitrates of the salts [18]. The absorption peaks $1236.38 \mathrm{~cm}^{-1}, 1180.10 \mathrm{~cm}^{-1}$, and $1026.51 \mathrm{~cm}^{-1}$ are generally carbonate groups $\left(\mathrm{CO}_{3}\right)$ [17]. The region of 1000 to $440 \mathrm{~cm}^{-1}$ shows the stretching frequencies of metal-oxygen functional groups [19]. Metal-oxygen (Ni-O) stretching vibrations modes were observed at 440.21 $\mathrm{cm}^{-1}$ and $554.28 \mathrm{~cm}^{-1}$, and confirmed the formation of $\mathrm{NiO}$ nanostructures [20]. 


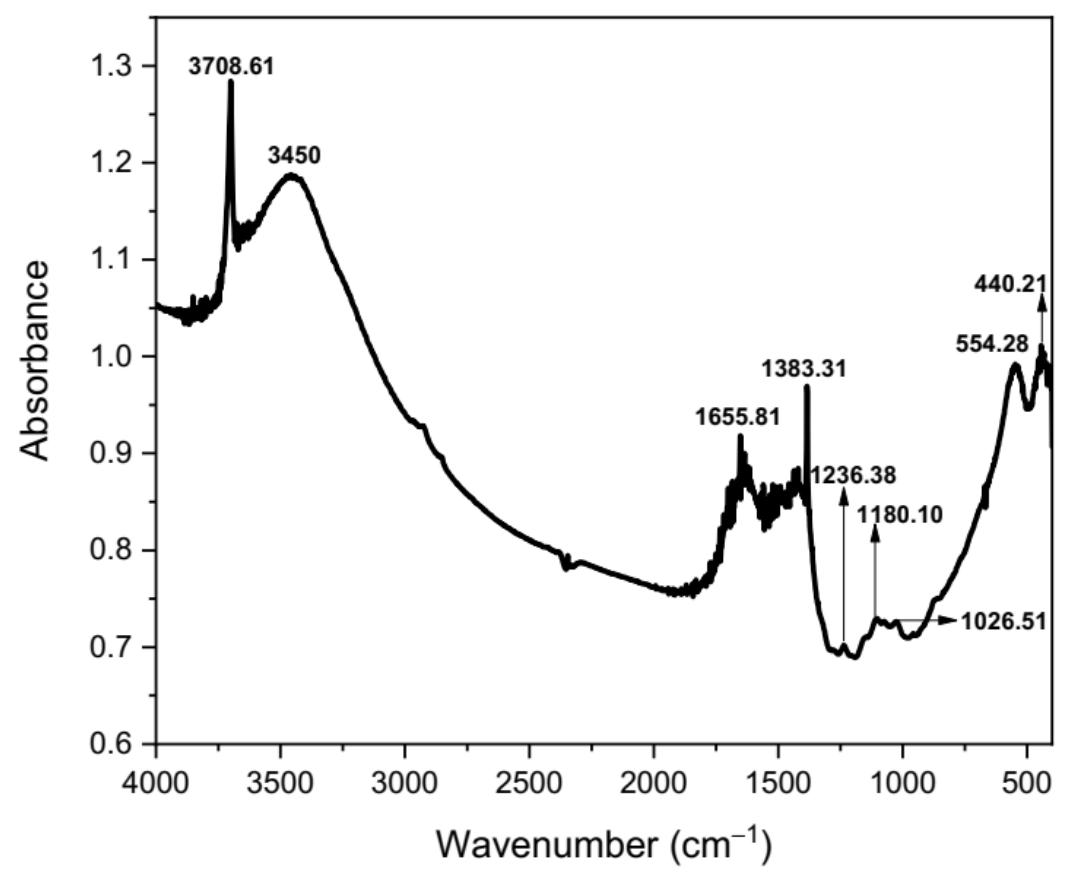

Figure 3. FTIR spectral analysis of biogenically synthesized NiO NPs.

\subsubsection{DRS Analysis}

To study the optical behavior of biogenically prepared NiO NPs, DRS technique was employed. The synthesized NiO NPs using Buxus wallichiana showed first absorption in UV-visible region and maximum absorption in IR region. Figure 4 presents the DRS spectrum of biogenic NiO NPs. The reflectance edge appeared at $645 \mathrm{~nm}$, which was almost similar to that reported in literature. The data collected from the spectral studies of the DRS spectrum were used to calculate the optical band gap energy of biologically produced $\mathrm{NiO}$ NPs by using the following formula:

$$
\mathrm{Eg}=\mathrm{hc} / \lambda
$$

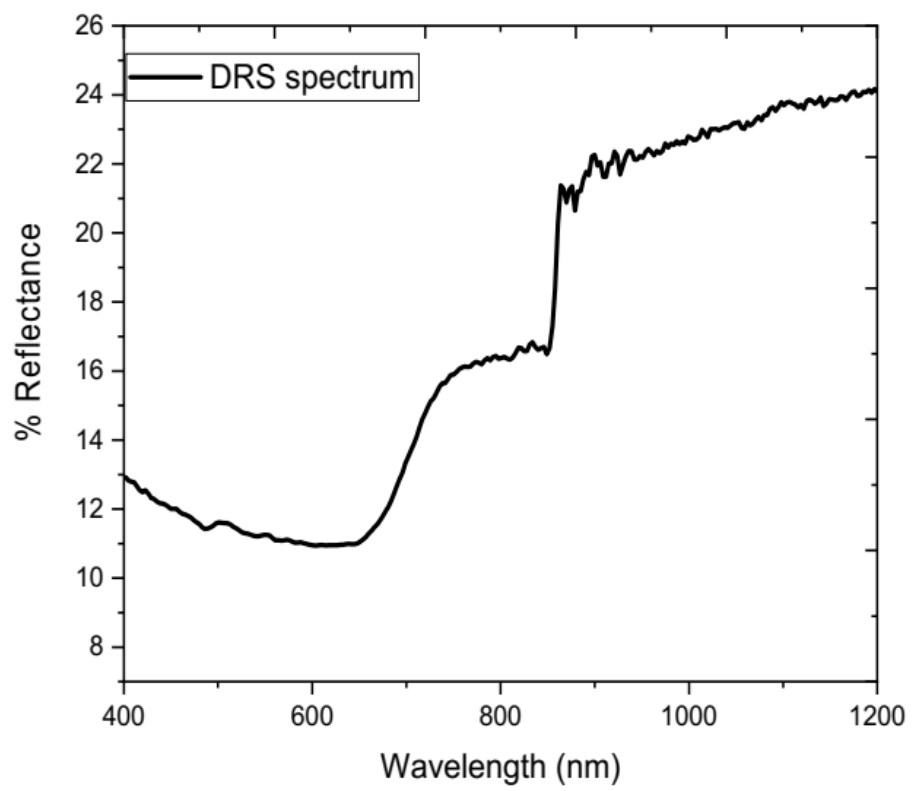

Figure 4. DRS spectrum of green synthesized NiO NPs. 
In Equation (4), Eg represents the optical band gap energy, $\mathrm{c}$ is the speed/velocity of light $\left(3 \times 10^{8} \mathrm{~m} \mathrm{~s}^{-1}\right), \mathrm{h}$ is Planck's constant $\left(6.626 \times 10^{-34} \mathrm{Js}\right)$, and $\lambda$ is band gap reflectance edge as listed in Table 2 [21]. The band gap reflectance edge was estimated by extrapolating the linear part of the spectrum back towards the $x$-axis of the plot between diffuse reflectance (\%) and wavelength $(\mathrm{nm})[10]$ and was calculated to be $645 \mathrm{~nm}$, showing the sample to be active in the visible region due to vibration, as well as excitation of electron at this particular wavelength [7]. In addition, the $1.99 \mathrm{eV}$ energy band gap of the produced sample was evaluated by Equation (4) (Figure 5). The recorded DRS spectrum of $\mathrm{NiO}$ NPs shows the substantial relationship towards the quantum confinement effect, which explains the increase in energy due to decrease in particle size. Thus, reduced particle size constitutes atoms on the surface of nanoparticles causing reduction of radioactive recombination of electron-hole pairs [20].

Table 2. Optical band gap energy of NiO NPs.

\begin{tabular}{cccc}
\hline Planck's Constant (h) & Velocity of Light (c) & $\begin{array}{c}\text { Band Gap } \\
\text { Reflectance Edge ( } \lambda \text { ) }\end{array}$ & $\begin{array}{c}\text { Optical Band Gap } \\
\text { Energy (Eg) }\end{array}$ \\
\hline $6.626 \times 10^{-34} \mathrm{Js}$ & $3 \times 10^{8} \mathrm{~ms}^{-1}$ & $645 \mathrm{~nm}$ & $1.99 \mathrm{eV}$ \\
\hline
\end{tabular}

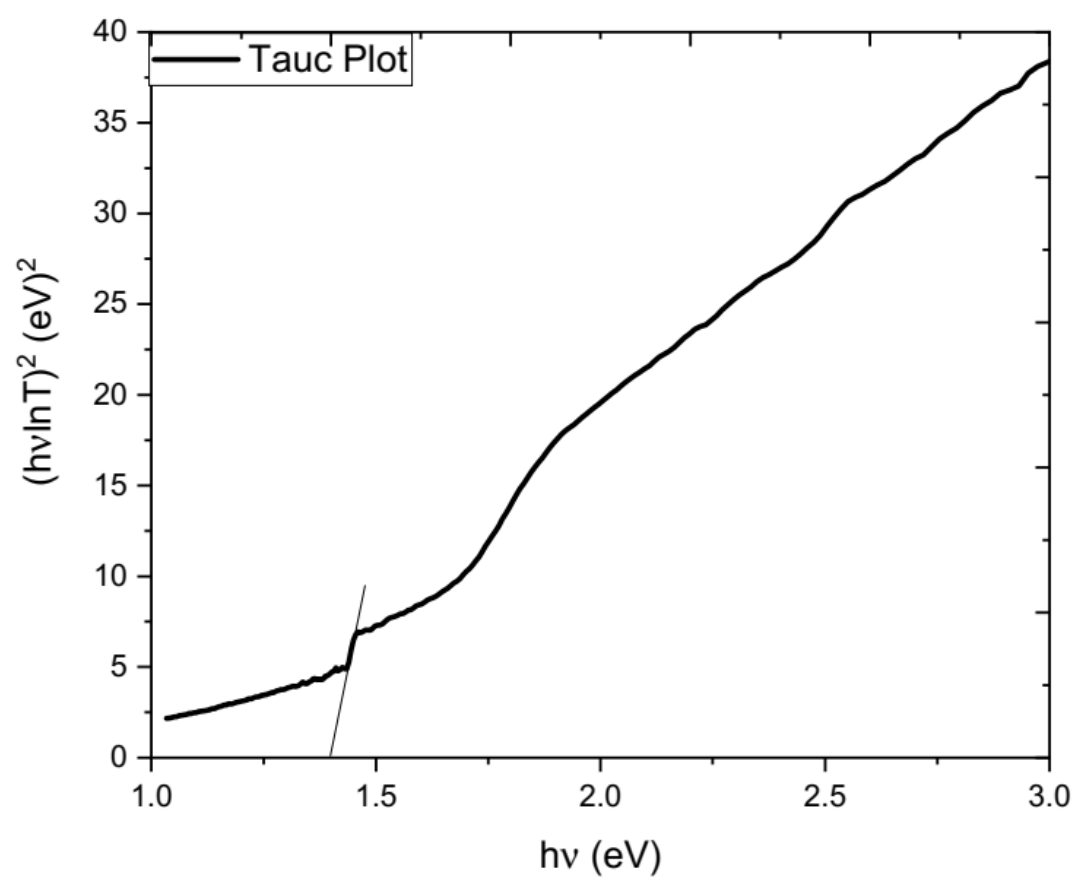

Figure 5. Tauc's plot of biogenically synthesized NiO NPs.

\subsubsection{SEM Analysis}

Morphological studies of biologically prepared NiO NPs were performed through SEM analysis. Figure 6 shows the spherical or nearly-spherical shape of NiO NPs with distinct boundaries, and the particle size analysis (PSA) calculated the average particle size to be $89.273 \mathrm{~nm}$ [18]. A closer look at these nano crystallites of biogenically synthesized $\mathrm{NiO}$ shows them to be aggregated clusters due to strong attractive forces which bring these particles closer to each other. A closer morphology was observed in the peel extract-assisted biometric synthesis of nickel oxide nanocrystals [22]. 


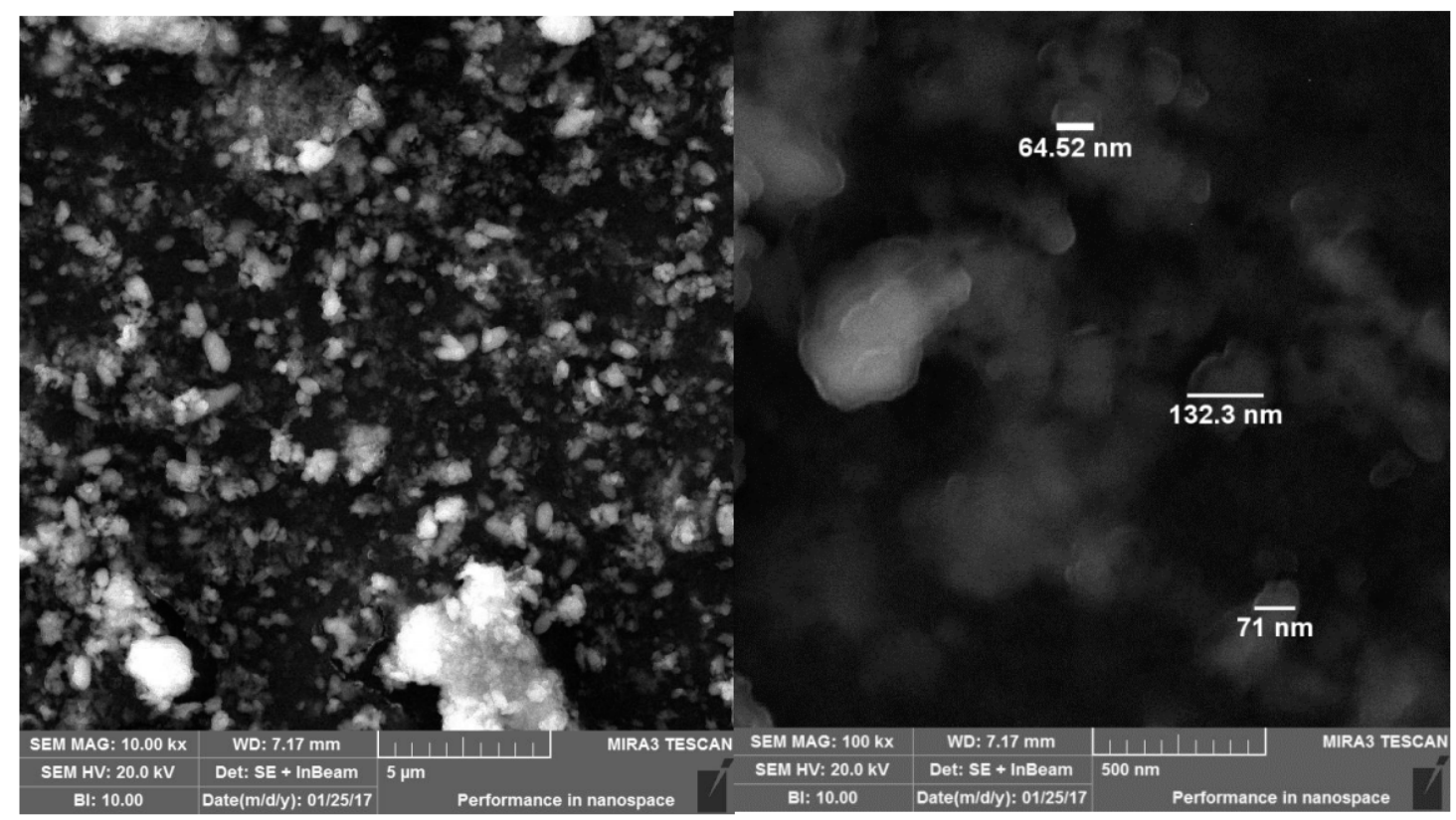

Figure 6. SEM images of green synthesized NiO NPs.

\subsubsection{EDX Analysis}

The percentage purity and elemental composition of biogenic NiO NPs was determined by EDX analysis, as shown in Figure 7. EDX analysis showed peaks of $\mathrm{Ni}$ and $\mathrm{O}$ with corresponding percentages of 75.6 and $20.9 \%$, respectively. The two strong peaks of $\mathrm{Ni}$ were observed between $7.9 \mathrm{keV}$ to $8.5 \mathrm{keV}$ and between $0.9 \mathrm{keV}$ to $1.0 \mathrm{keV}$. EDX displayed the peaks of impurities such as $\mathrm{Cl}$ at $3 \mathrm{keV}$, Si at $2 \mathrm{keV}, \mathrm{Na}$ at $1.9 \mathrm{keV}$, and $\mathrm{O}$ at $0.6 \mathrm{keV}$. Elements such as $\mathrm{Cl}(3.0 \%), \mathrm{Na}(0.5 \%)$, and $\mathrm{Si}(0.1 \%)$ were observed as impurities from the glass instruments/apparatus on which the NiO NPs sample was coated. Similarly, a peak of carbon was observed at $0.4 \mathrm{keV}$ due to the carbon tape used for sticking of the sample [18].

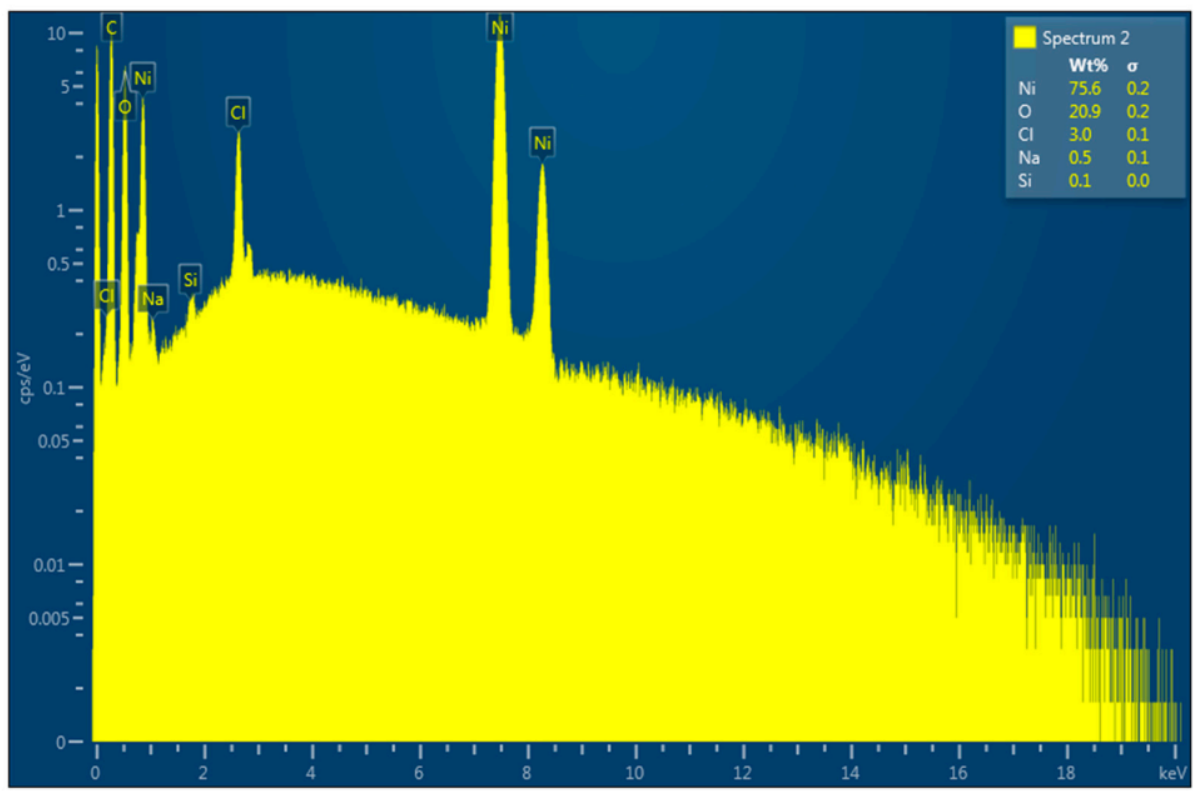

Figure 7. EDX spectrum of the NiO NPs. 


\subsubsection{TGA Analysis}

TGA analyzed the thermal stability and percent weight loss of the biogenic NiO NPs. A total of $19.81 \%$ weight loss was found for the NiO NPs. From the TGA graph (Figure 8), the weight loss and decomposition of gel can be seen to be divided into three different stages. The first loss of $0.52 \mathrm{mg}$ in the temperature range of 40 to $160^{\circ} \mathrm{C}$ can be attributed to the evaporation of moisture, decomposition, and loss of hydroxyl group or water molecules. A sudden second weight loss of $0.63 \mathrm{mg}$ was observed in the temperature range of 160 to $615{ }^{\circ} \mathrm{C}$ and is due to the decomposition of $\mathrm{NiO}$ gel nearly at $400{ }^{\circ} \mathrm{C}$ [23]. Similarly, a continuous third weight loss in the temperature range of 615 to $890^{\circ} \mathrm{C}$ is due to the formation of NiO NPs [23]. No further weight loss was observed after $890^{\circ} \mathrm{C}$.

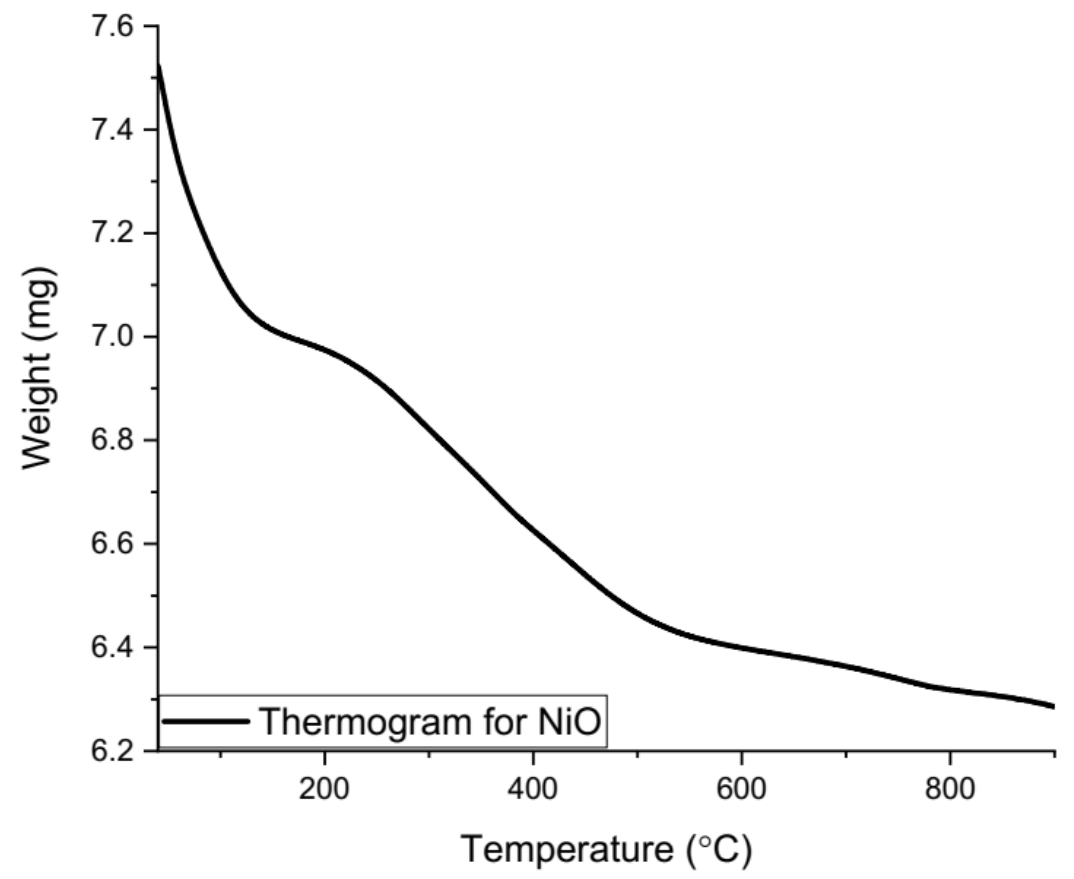

Figure 8. TGA graph of green synthesized NiO NPs.

\subsection{Biological Activities}

\subsubsection{Antioxidant Activity}

Figure 9 shows the antioxidant activity (ABTS free radical scavenging) of biogenic $\mathrm{NiO}$ NPs performed at different doses $(100-400 \mu \mathrm{L})$ of NiO NPs. ABTS assay displayed the potential scavenging activity of $\mathrm{NiO} N$ Ps towards reactive oxygen species (ROS). Strong ABTS scavenging power $(71 \%)$ was recorded at $400 \mu \mathrm{L}$ for biogenic NiO NPs. In current studies, the aqueous solution of Buxus wallichiana acted as a good oxidizing, reducing, and capping agent. This plant, while acting as good antioxidant species, also enhances the oxidation reduction potential of NiO NPs. The resultant NPs show distinctive antioxidant potential and reduce the oxidative stress. Figure 9 shows that with increasing the concentration of biogenic NiO NPs, the percentage scavenging effect of NiO NPs also increases. The ratio of the scavenging activity of $\mathrm{NiO} \mathrm{NPs}$ at $300 \mu \mathrm{L}(59 \%), 200 \mu \mathrm{L}(47 \%)$, and $100 \mu \mathrm{L}(31 \%)$ was observed with $234.84 \mathrm{IC}_{50}$ value as shown in Table 3. Various compounds such as terpenoid, polar flavonoid, nonpolar flavonoid, tannin, saponin, phenol, and ascorbic acid, which are present in Buxus wallichiana, might have participated in the reduction and stabilization of biogenically synthesized NiO NPs [24-26]. The percentage radical scavenging activity was determined by using Equation (1). 


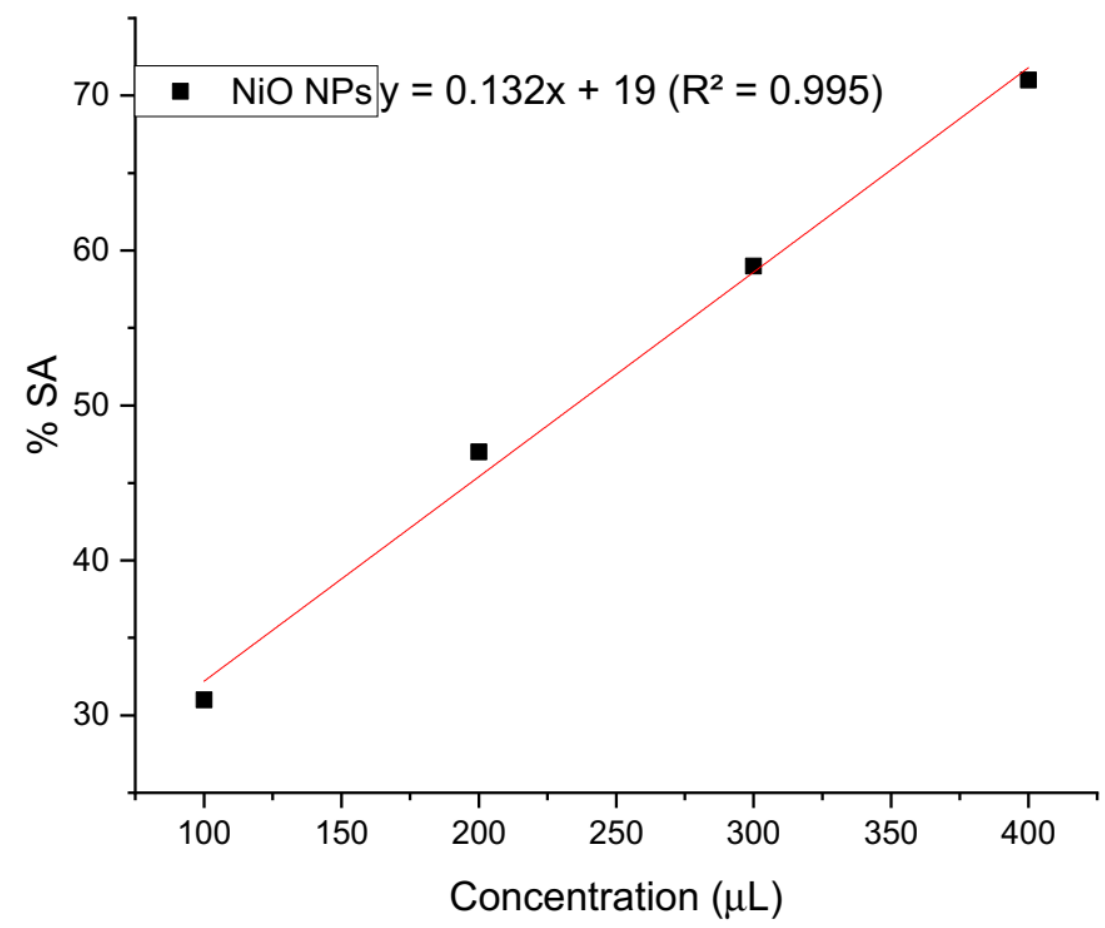

Figure 9. Graphical representation of antioxidant activity of green synthesized NiO NPs.

Table 3. Percentage scavenging activity (\%) of biogenic NiO NPs.

\begin{tabular}{cccc}
\hline Samples Code & Concentration $(\mu \mathrm{L})$ & \% Scavenging Activity & IC $_{\mathbf{5 0}}$ \\
\hline \multirow{2}{*}{ NiO NPs } & 100 & 31 & \\
& 200 & 47 & 234.84 \\
& 300 & 59 & \\
\hline
\end{tabular}

\subsubsection{Bactericidal Activity}

To test the antibacterial effect of NiO NPs by agar well diffusion method, the zone of inhibition formed around each well was measured in $\mathrm{mm}$. The inhibitory effect of biosynthesized NiO NPs with three different concentrations $(25 \mu \mathrm{L}, 50 \mu \mathrm{L}$, and $75 \mu \mathrm{L})$ was analyzed as shown in Figure $10 \mathrm{a}-\mathrm{d}$ and Table 4. No replicated experiment was performed. Two Gram-positive (B. subtilis and B. licheniformis) and two Gram-negative (E. coli and K. pneumoniae) bacteria were used in these analyses. Here, $\mathrm{C}$ is the solvent (DMSO) that showed zero inhibition. These results show that by increasing the concentration of suspensions in each well, antibacterial effect of NiO NPs is also enhanced. B. subtilis and $B$. lichenifornis were found to be the most susceptible strain with significant antibacterial activity observed in the case of Bacillus subtilis, while K. pneumoniae was found to be the least susceptible strain. Usually, the antibacterial phenomenon depends on nano size of particle, large surface area, reactive radicals $\left(\mathrm{Ni}^{2+}\right)$, and reactive oxygen species (ROS). The nanoparticles of $\mathrm{Ni}$ are well-known antibiotics having the ability to produce reactive oxygen species (ROS) such as superoxide, peroxide, hydroxyl radicals, and singlet/alpha oxygen following the Fenton reaction. These ROS, when attacking on bacterial/pathogens surface, cause damage of DNA, peroxidation of lipid, oxidation of protein, and death of bacterial cells $[10,27]$. 


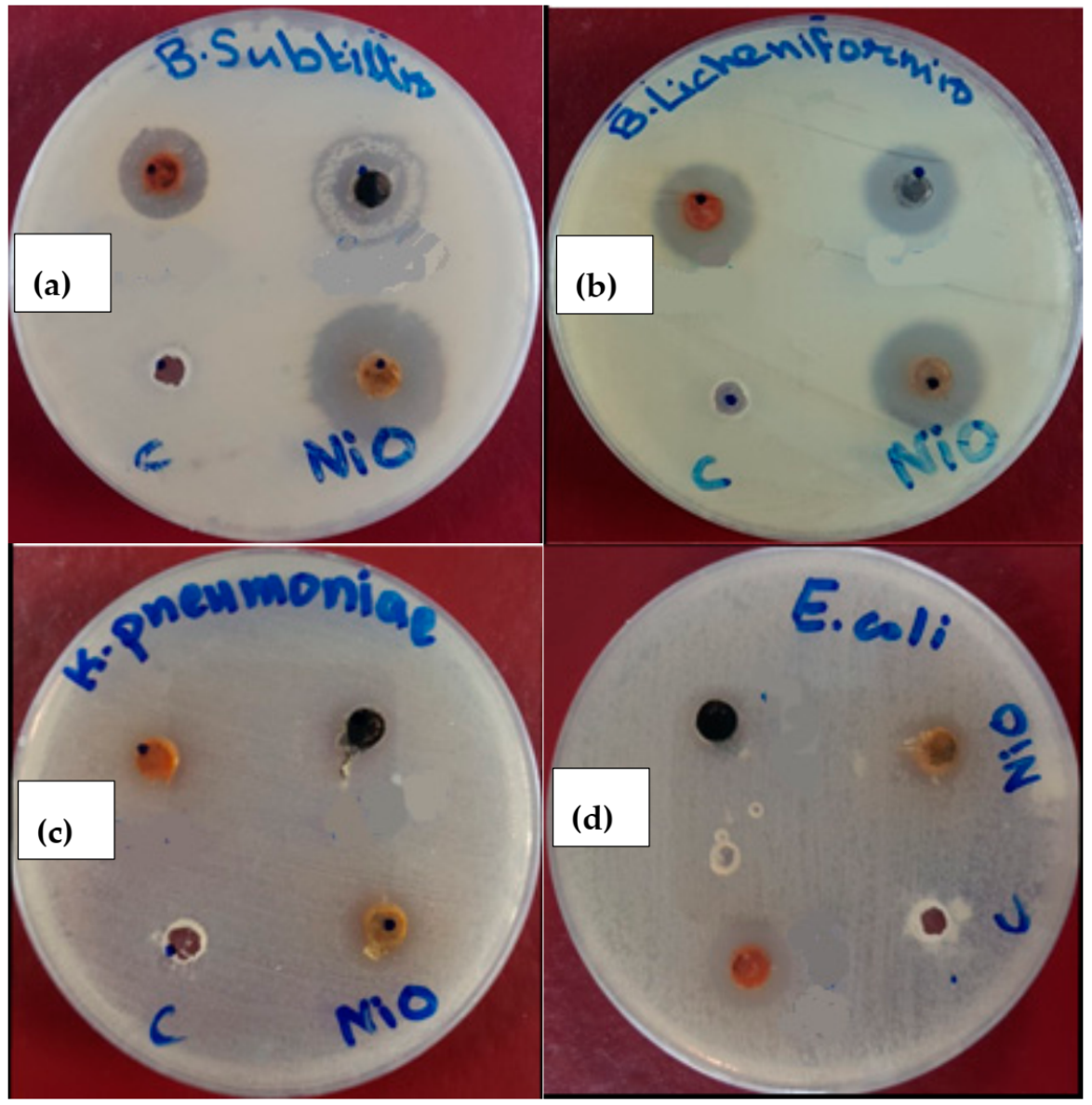

Figure 10. Experimental photographs of antibacterial activity of biogenic NiO NPs against Grampositive (B. subtilis (a) and B. licheniformis (b)) and Gram-negative bacteria (K. pneumoniae (c) and E. coli (d)).

Table 4. Antibacterial activity of NiO NPs against Gram-positive and Gram-negative bacteria at different concentrations; the activity is shown in millimeter $(\mathrm{mm})$, no replicated experiment was performed. The correlation between utilized dose and obtained data was studied by applying $t$ test.

\begin{tabular}{|c|c|c|c|c|c|}
\hline \multirow{2}{*}{ Microorganism } & \multicolumn{3}{|c|}{ Volume of NiO Suspension } & \multirow{2}{*}{$\begin{array}{c}\text { Correlation between Utilized } \\
\text { Dose and Obtained Data }(p=0.05)\end{array}$} & \multirow{2}{*}{$\begin{array}{c}\text { C = Solvent } \\
\text { DMSO }\end{array}$} \\
\hline & $25 \mu \mathrm{L}$ & $50 \mu \mathrm{L}$ & $75 \mu \mathrm{L}$ & & \\
\hline B. subtilis & 10.72 & 17.38 & 23.83 & 0.046 & 00 \\
\hline B. licheniformis & 8.01 & 12.93 & 18.57 & 0.042 & 00 \\
\hline K. pneumoniae & 00 & 01 & 2.08 & 0.036 & 00 \\
\hline E. coli & 2.10 & 4.95 & 8.23 & 0.035 & 00 \\
\hline
\end{tabular}

The antibacterial activity of NiO NPs reported in this study was compared with literature and the data is listed in Table 5, which shows NiO NPs that were synthesized via green method previously. The reported data shows that the present reported NiO NPs exhibit significantly higher antibacterial activity against Gram-positive bacteria compared to the reported data. Moreover, the NiO NPs reported previously were only tested for their antibacterial potential, whereas the $\mathrm{NiO}$ NPs reported in this study were evaluated for both antibacterial and antioxidant activities. 
Table 5. Comparison of the present work with the reported data for NiO NPs.

\begin{tabular}{|c|c|c|c|c|c|}
\hline S. No & Methods & $\begin{array}{l}\text { Particle Size } \\
\quad(\mathrm{nm})\end{array}$ & $\begin{array}{c}\text { Activity against } \\
\text { Gram-Negative Bacteria }\end{array}$ & $\begin{array}{c}\text { Activity against } \\
\text { Gram-Positive Bacteria }\end{array}$ & References \\
\hline 01 & Green synthesis & 23.21 & $\begin{array}{c}9 \mathrm{~mm} \\
\text { (E. hermannii) }\end{array}$ & $\begin{array}{c}21 \mathrm{~mm} \\
(\text { S. aureus })\end{array}$ & [20] \\
\hline 02 & Green synthesis & 20 to 50 & $\begin{array}{l}16 \mathrm{~mm} \\
\text { (E. coli) }\end{array}$ & $\begin{array}{c}12 \mathrm{~mm} \\
\text { (B. subtilis) }\end{array}$ & [28] \\
\hline 03 & Green synthesis & 20 to 50 & $\begin{array}{l}16 \mathrm{~mm} \\
\text { (E. coli) }\end{array}$ & $\begin{array}{c}12 \mathrm{~mm} \\
\text { (B. subtilis) }\end{array}$ & [29] \\
\hline 04 & Green synthesis & 89.28 & $\begin{array}{c}8.23 \\
\text { (E. coli) }\end{array}$ & $\begin{array}{c}23.83 \\
\text { (B. subtilis) }\end{array}$ & Present study \\
\hline
\end{tabular}

\section{Conclusions}

In the current investigation, Buxus wallichiana acted as stabilizing, reducing, and capping agent for successful formation of biogenic NiO NPs. Both XRD and EDX determined the synthesis of NiO NPs as well as the nano size of the nanoparticles, whereas EDX confirmed the absence of impurities in these nanoparticles. FTIR also confirmed Ni-O bond, suggesting the successful formation of NiO. SEM verified the nano-range particle size of these nanoparticles with slight agglomeration. Moderate percentage scavenging activity of nano-sized $\mathrm{NiO}$ was observed at different concentrations with $234.84 \mathrm{IC}_{50}$ value. Bacillus lichenifornis and Bacillus subtilis were found to be the most susceptible strain, while Klebsiella pneumoniae was shown to be the least susceptible strain in the zone of inhibition. Thus, it can be concluded that these biogenically-produced NiO NPs have the potential to play a positive role in the control and reduction of various endemic, pandemic, cancerous, and carcinogenic diseases.

Author Contributions: Conceptualization, S.H., S.U.D. and P.A.; methodology, S.H.; software, S.A.M.A.; validation, P.A., M.U.K. and H.O.E.; formal analysis, H.I.; investigation, S.H.; resources, S.U.D.; data curation, P.A.; writing-original draft preparation, H.I., F.F.A.-H. and T.K.Z.E.-A.; writing-review and editing, S.H. and M.U.K.; visualization, S.H.; supervision, S.U.D.; project administration, S.U.D.; funding acquisition, H.O.E., F.F.A.-H. and S.A.M.A. All authors have read and agreed to the published version of the manuscript.

Funding: Princess Nourah bint Abdulrahman University Researchers Supporting Project (Grant No. PNURSP2022R55).

Data Availability Statement: Not applicable.

Acknowledgments: The authors express their gratitude to Princess Nourah bint Abdulrahman University Researchers Supporting Project (Grant No. PNURSP2022R55), Princess Nourah bint Abdulrahman University, Riyadh, Saudi Arabia.

Conflicts of Interest: The authors declare no conflict of interest.

\section{References}

1. Din, M.I.; Nabi, A.G.; Rani, A.; Aihetasham, A.; Mukhtar, M. Single step green synthesis of stable nickel and nickel oxide nanoparticles from Calotropis gigantea: Catalytic and antimicrobial potentials. Environ. Nanotechnol. Monit. Manag. 2018, 9, 29-36. [CrossRef]

2. Chen, Z.; Wang, Q.; Zhang, Z.; Lei, H. Preparation and properties of antibacterial fluorinated acrylic emulsion. React. Funct. Polym. 2021, 163, 104901. [CrossRef]

3. Hafeez, M.; Shamim, W.; Ehsan, R.; ul Abdin, Z.; Din, S.U.; Haq, S.; Khan, A.; Shahida, S.; Hameed, U. Structural and biological investigation of biogenically synthesized titanium dioxide nanoparticles: Calcination and characterization. Microsc. Res. Tech. 2021, 84, 2372-2380. [CrossRef] [PubMed]

4. Wang, X.D.; Wei, W.; Wang, P.F.; Tang, Y.T.; Deng, R.C.; Li, B.; Zhou, S.S.; Zhang, J.W.; Zhang, L.; Xiao, Z.P.; et al. Novel 3-arylfuran-2(5H)-one-fluoroquinolone hybrid: Design, synthesis and evaluation as antibacterial agent. Bioorg. Med. Chem. 2014, 22, 3620-3628. [CrossRef] 
5. Haq, S.; Rehman, W.; Waseem, M.; Meynen, V.; Awan, S.U.; Saeed, S.; Iqbal, N. Fabrication of pure and moxifloxacin functionalized silver oxide nanoparticles for photocatalytic and antimicrobial activity. J. Photochem. Photobiol. B Biol. 2018, 186, 116-124. [CrossRef]

6. Stankic, S.; Suman, S.; Haque, F.; Vidic, J. Pure and multi metal oxide nanoparticles: Synthesis, antibacterial and cytotoxic properties. J. Nanobiotechnol. 2016, 14, 73. [CrossRef]

7. Shah, A.; Haq, S.; Rehman, W.; Muhammad, W.; Shoukat, S.; Rehman, M. ur Photocatalytic and antibacterial activities of Paeonia emodi mediated silver oxide nanoparticles. Mater. Res. Express 2019, 6, 045045. [CrossRef]

8. Xiao, Z.P.; Wei, W.; Wang, P.F.; Shi, W.K.; Zhu, N.; Xie, M.Q.; Sun, Y.W.; Li, L.X.; Xie, Y.X.; Zhu, L.S.; et al. Synthesis and evaluation of new tyrosyl-tRNA synthetase inhibitors as antibacterial agents based on a N2-(arylacetyl)glycinanilide scaffold. Eur. J. Med. Chem. 2015, 102, 631-638. [CrossRef]

9. Zorkipli, N.N.M.; Kaus, N.H.M.; Mohamad, A.A. Synthesis of NiO Nanoparticles through Sol-gel Method. Procedia Chem. 2016, 19, 626-631. [CrossRef]

10. Rajith Kumar, C.R.; Betageri, V.S.; Nagaraju, G.; Pujar, G.H.; Suma, B.P.; Latha, M.S. Photocatalytic, nitrite sensing and antibacterial studies of facile bio-synthesized nickel oxide nanoparticles. J. Sci. Adv. Mater. Devices 2020, 5, 48-55. [CrossRef]

11. Wei, W.; Shi, W.K.; Wang, P.F.; Zeng, X.T.; Li, P.; Zhang, J.R.; Li, Q.; Tang, Z.P.; Peng, J.; Wu, L.Z.; et al. Adenosine analogs as inhibitors of tyrosyl-tRNA synthetase: Design, synthesis and antibacterial evaluation. Bioorg. Med. Chem. 2015, 23, 6602-6611. [CrossRef]

12. Haq, S.; Dildar, S.; Ali, M.B.; Mezni, A.; Hedfi, A.; Shahzad, M.I.; Shahzad, N.; Shah, A. Antimicrobial and antioxidant properties of biosynthesized of $\mathrm{NiO}$ nanoparticles using Raphanus sativus (R. sativus) extract. Mater. Res. Express 2021, 8, 055006. [CrossRef]

13. Pant, S. Buxus wallichiana L., a multipurpose Himalayan tree in peril. Int. J. Biodivers. Conserv. 2015, 3, 175-177.

14. Perachiselvi, M.; Jenson Samraj, J.; Bagavathy, S.; Feiona, T.A.; Krishnaveni, P.; Laksmi, E.P.; Swetha, V.; Leema, M.M.; Britto, S.J.; Annadurai, G. Fabrication of Nickel Oxide Nanoparticles for Ntibacterial and Photocatalytic Activity. Res. J. Pharm. Biol. Chem. Sci. 2018, 4, 749-760. [CrossRef]

15. Haq, S.; Abbasi, F.; Ben Ali, M.; Hedfi, A.; Mezni, A.; Rehman, W.; Waseem, M.; Khan, A.R.; Shaheen, H. Green synthesis of cobalt oxide nanoparticles and the effect of annealing temperature on their physiochemical and biological properties. Mater. Res. Express 2021, 8, 075009. [CrossRef]

16. Elhaddad, E.; Rehman, W.; Waseem, M.; Nawaz, M.; Haq, S.; Guo, C.Y. Fabrication of Highly Efficient $\mathrm{Bi}_{2} \mathrm{Sn}_{2} \mathrm{O}_{7} / \mathrm{C}_{3} \mathrm{~N}_{4} \mathrm{Composite}$ with Enhanced Photocatalytic Activity for Degradation of Organic Pollutants. J. Inorg. Organomet. Polym. Mater. 2020, 31, 172-179. [CrossRef]

17. Lingaraju, K.; Raja Naika, H.; Nagabhushana, H.; Jayanna, K.; Devaraja, S.; Nagaraju, G. Biosynthesis of Nickel oxide Nanoparticles from Euphorbia heterophylla (L.) and their biological application. Arab. J. Chem. 2020, 13, 4712-4719. [CrossRef]

18. Anand, G.T.; Nithiyavathi, R.; Ramesh, R.; John Sundaram, S.; Kaviyarasu, K. Structural and optical properties of nickel oxide nanoparticles: Investigation of antimicrobial applications. Surf. Interfaces 2020, 18, 100460. [CrossRef]

19. Abdallah, A.M.; Basma, H.; Awad, R. Preparation, Characterization, and Application of Nickel Oxide Nanoparticles in Glucose and Lactose Biosensors. Mod. Appl. Sci. 2019, 13, 99. [CrossRef]

20. Ezhilarasi, A.A.; Vijaya, J.J.; Kaviyarasu, K.; Zhang, X.; Kennedy, L.J. Green synthesis of nickel oxide nanoparticles using Solanum trilobatum extract for cytotoxicity, antibacterial and photocatalytic studies. Surf. Interfaces 2020, 20, 100553. [CrossRef]

21. Shoukat, S.; Haq, S.; Rehman, W.; Waseem, M.; Shahzad, M.I.; Shahzad, N.; Hafeez, M.; Din, S.U.; ul-Abdin, Z.; Shah, A.; et al. Fabrication and Characterization of Zinc Titanate Heterojunction for Adsorption and Photocatalytic Applications. J. Inorg. Organomet. Polym. Mater. 2020, 30, 4944-4953. [CrossRef]

22. Yuvakkumar, R.; Suresh, J.; Nathanael, A.J.; Sundrarajan, M.; Hong, S.I. Rambutan (Nephelium lappaceum L.) peel extract assisted biomimetic synthesis of nickel oxide nanocrystals. Mater. Lett. 2014, 128, 170-174. [CrossRef]

23. Sabouri, Z.; Akbari, A.; Hosseini, H.A.; Hashemzadeh, A.; Darroudi, M. Eco-Friendly Biosynthesis of Nickel Oxide Nanoparticles Mediated by Okra Plant Extract and Investigation of Their Photocatalytic, Magnetic, Cytotoxicity, and Antibacterial Properties. J. Clust. Sci. 2019, 30, 1425-1434. [CrossRef]

24. Abbasi, B.A.; Iqbal, J.; Mahmood, T.; Ahmad, R.; Kanwal, S.; Afridi, S. Plant-mediated synthesis of nickel oxide nanoparticles (NiO) via Geranium wallichianum: Characterization and different biological applications. Mater. Res. Express 2019, 6. [CrossRef]

25. Hamid, A.; Haq, S.; Ur Rehman, S.; Akhter, K.; Rehman, W.; Waseem, M.; Ud Din, S.; ul-Abdin, Z.; Hafeez, M.; Khan, A.; et al. Calcination temperature-driven antibacterial and antioxidant activities of fumaria indica mediated copper oxide nanoparticles: Characterization. Chem. Pap. 2021, 75, 4189-4198. [CrossRef]

26. Haq, S.; Ahmad, P.; Khandaker, M.U.; Faruque, M.R.I.; Rehman, W.; Waseem, M.; Din, S.U. Antibacterial, antioxidant and physicochemical investigations of tin dioxide nanoparticles synthesized via microemulsion method. Mater. Res. Express 2021, 8. [CrossRef]

27. Rehman, F.U.; Mahmood, R.; Ali, M.B.; Hedfi, A.; Mezni, A.; Haq, S.; Din, S.U.; Ehsan, R. Physicochemical, Photocatalytic, Antibacterial, and Antioxidant Screening of Bergenia Ciliata Mediated Nickel Oxide Nanoparticles. Crystal 2021, $11,1137$. [CrossRef] 
28. Srihasam, S.; Thyagarajan, K.; Korivi, M.; Lebaka, V.R.; Mallem, S.P.R. Phytogenic generation of NiO nanoparticles using stevia leaf extract and evaluation of their in-vitro antioxidant and antimicrobial properties. Biomolecules 2020, 10, 89. [CrossRef]

29. Ramalingam, R.; Hussain, M.; Turabe, U.; Kumar, N.; Deivi, K. Green synthesis, characterization and antibacterial evaluation of electrospun nickel oxide nanofibers. Mater. Lett. 2019, 256, 126616. [CrossRef] 